individuals with risk factors selected by stepwise logistic regression, followed by validation on another data with the same number.

Results The overall cumulative non-visit rates at 3, 6, 9, and 12 months were $91.4 \%, 88.2 \%, 86.2 \%$, and $84.4 \%$, respectively. The disease-specific rates at 12 months were $84.3 \%$ for HT, $67.9 \%$ for DM, and $86.1 \%$ for DL. Limiting the analysis to those with extremely high blood pressure (BP) (systolic BP $\geq 160 \mathrm{mmHg}$ ), blood glucose levels (HbA1c $\geq 8.4 \%$ ), or lipid levels (LDL-cholesterol levels $\geq 160 \mathrm{mg} / \mathrm{dL}$ ) resulted in a slightly lower overall rate at 12 months $(74.0 \%)$, with a relatively low rate for DM (51.9\%). The prediction model, including factors such as age, working status, dietary habits, and the motivation of behavioural change showed modest discrimination ability for the pattern of visits to medical institutions $(\mathrm{AUC}=0.63)$, and well calibrated in validation data (Hosmer-Lemeshow $\mathrm{p}=0.38$ ).

Conclusion Our study demonstrated that over $80 \%$ of Japanese individuals with lifestyle-related diseases did not visit medical institutions for 1 year after health check-ups. The pattern of visits to medical institutions model may be used for precision health counselling guidance for occupational health providers, which is a promising strategy to encourage individuals with lifestyle-related diseases to prevent diseases exacerbations.

\section{SCIENTIFIC INTEGRITY AND JOURNAL PUBLICATION PRACTICE IN OCCUPATIONAL HEALTH}

Leslie London*. School of Public Health and Family Medicine, University of Cape Town, South Africa

\subsection{6/oemed-2018-ICOHabstracts.440}

Introduction Unbiased dissemination of research findings is essential to inform evidence-based policy in occupational health. For that reason, independence of journals from vested interests is essential for good publication practice. The Committee on Publication Ethics (COPE) produces guidelines aimed at protecting the integrity of scientific research publication. Widely publicised cases involving journal failure to address Conflict of Interest in occupational health suggest that adherence to COPE guidelines may be limited. This study reviewed the published guidelines of 34 selected journals publishing on occupational health for stated adherence to ethical guidelines.

Methods From the first 60 citations generated from a PubMed Search on occupational hazards of pesticides, 46 journals were identified. After exclusion of disciplinary journals (e.g. on paediatrics, orthopaedics), non-English language journals and national/regional journals, a sample of 34 journals was generated. On-line instructions for authors, journal information and publication policies for these journals were reviewed and compared to the COPE Guidelines for attention to (a) editorial independence; (b) definition of conflict of interest.

Result Of the 34 journals, 16 (47\%) reported following COPE guidelines; Only 3 journals (9\%) explicitly cited editorial independence on their platform. Most journals (85\%) explicitly provide for Conflict of Interest (CoI) procedures but most of those $(90 \%)$ defined $\mathrm{CoI}$ in financial terms only with just under half (48\%) recognising other forms of CoI.

Discussion Publication practices across journals are highly variable. Editorial independence appears either to be assumed or be of less importance to journals in the field, who concentrate their attention on financial conflict of interest declarations. Such practices may not be sufficient to maintain scientific integrity in the dissemination of research findings and in supporting evidence based occupational health policy.

\section{MANAGEMENT SUPPORT FOR AN OCCUPATIONAL HEALTH AND SAFETY PROGRAMME - A MYTH OR REALITY?}

Louwna Pretorius*. Corobrik Pty (Ltd), Edenvale, South Africa

\subsection{6/oemed-2018-ICOHabstracts.441}

Introduction The success of an occupational health and safety programme depends on many factors, most notably the support of managers at all three levels, executive (top), middle and operational management is required to ensure a healthy and safe workplace.

Methods A phenomenological, exploratory, descriptive and contextual approach was followed by means of individual, indepth, unstructured interviews. Purposive sampling was used in the accessible population of Occupational health nurse practitioners of the Pretoria region $(n=30)$ from 8 manufacturing settings and the inclusion criteria of the sample was occupational health nursing practitioners(OHNP's) with a post basic qualification, in occupational health nursing, and practicing as OHNP's for at least 3-5 years in a manufacturing environment.

Results The lived experiences of OHNPs on the support of managers in an occupational health and safety programme in the manufacturing environment are interwoven within an organisational environment displaying tension between employee safety and productivity as evidenced in the OHNP's relationship with the organisational environment, the OHNPs relationship with line management, head office and top management and finally the relationship with the self.

Discussion The findings suggest that the road to constructive support for the OHNP in an occupational health and safety programme runs through holistic support structures which are able to harmonise the nature of the external organisational context, availability of resources, relationship with line management in the role of the OHS and OHNP as well as their own legal liability in their lack of understanding of the related legislative requirements. The role of the management style in fostering or inhibiting support was highlighted as well as the propensity of the OHNP towards self- management.

\section{CONTINUOUS QUALITY IMPROVEMENT (CQI) AS AN ALTERNATIVE TO STANDARD SETTING: THE DEMING CYCLE (PDCA) APPROACH TO ACHIEVING RISK REDUCTION}

Tee Guidotti. Occupational + Environmental Health and Safety, Washington, DC, USA

\subsection{6/oemed-2018-ICOHabstracts.442}

Current approaches to regulatory risk management based on standard-setting assume that the standard represents a permanent best practice and a level of risk that is appropriate for the level of protection required by the community at risk. However, new information, improved scientific methodology, and the identification of novel risks often require review and 
modification of standards for significant hazards. As well, social attitudes change and society generally becomes more risk-averse over time. An alternative approach is 'continuous quality improvement' (CQI), which is an on-going process for the optimisation of risk, efficiency of operations, and consumption of resources. The 'Deming Cycle' (Plan $\rightarrow \mathrm{Do} \rightarrow$ Study $\rightarrow$ Act $\rightarrow$ [repeat]), for example, is the standard management approach for quality assurance in the private sector. CQI has advantages over fixed standard setting in improving the quality of the environment and worker health and fits better with good management practices. The theoretical disadvantages may be business concern over an ever shifting target for compliance and the opportunity cost of making improvements when performance is already sufficient. However, in practice, CQI has shown such great benefit in improving the operations of enterprises from small business to large corporations that it is standard procedure and typically results in large unanticipated gains beyond quality, in efficient operations, lower cost, and reduced risk. This approach is rarely used in occupational health protection but it has been adopted as 'Best Available Control Technology' in other settings. In the United States, the mandated periodic review of ambient air quality standards by the EPA and of high-priority chemicals under the Lautenberg Chemical Safety Act are broadly compatible with CQI. The approach is also one means of effectively operationalizing the Precautionary Principle. It is suggested that CQI should be reconsidered as an alternative regulatory approach and adopted as a fundamental approach to risk management.

\section{WOMEN HEALTH AND WORK}

${ }^{1}$ Ravindra Kumar*, ${ }^{2}$ Pragati Patil, ${ }^{3}$ Shriniket Mishra, ${ }^{4}$ Anoop Singh. ${ }^{1}$ Hero MotoCorp Ltd, Neemrana, India; ${ }^{2}$ Indian Army, India; ${ }^{3}$ Chief Medical Officer, Hero MotoCorp Ltd; ${ }^{4}$ Assistant Professor, Dr SN Medical College Jodhpur

\subsection{6/oemed-2018-ICOHabstracts.443}

Introduction India, Women working on shop floor is new concept for Automobile industries. women taking up tools to partake in manufacturing of two-wheelers, hitherto a male bastion. As the call for women empowerment gets louder, Automobile two-wheeler manufacturers are responding with an aim to create a culture where women can stand shoulder to shoulder with their male counterparts to contribute to the growth of the company. Occupational health Centre is concerned about their health, a cross-sectional scientific study conducted in an automobile industry to assess Body Mass Index with an aim to make healthy work pattern suitable to their physiology.

Method Study was conducted on 27 randomly selected unmarried women work team member in age group of 19-24 years of frame assembly section in an automobile industry. Job was working on assembly line of two wheeler of automobile manufacturing industry. Parts pick from conveyor tray and to mounting on frame body of two-wheeler. Measure the weight and height and then calculate the BMI of the team member were computed at the time of joining and after 6 month of staring work, general clinical check-up including heart rate, and oxygen saturation and BP monitoring before and after the 6 month interval of work schedule.

Results Women working on shop floor mean age 21.5 years, mean weight $44.40 \mathrm{~kg}$ and mean height $161.66 \mathrm{~cm}$ and mean BMI 18.28 taking balance and with 8 hours shift duty, leave as per prorota basis, 48 hours work in one week. Review periodical medical examination after 6 month found mean height 161.66 and mean weight $50.30 \mathrm{~kg}$ and mean BMI 20.88 .

Conclusion This is first surveillance of women health status in automobile industry in India under occupational health physician. Taking balance diet with structured work pattern with appropriate work atmosphere result in improved average BMI.

\section{THE STRESS CHECK PROGRAM: AN EVALUATION OF THE FIRST-YEAR IMPLEMENTATION OF THE NEW NATIONAL WORKPLACE MENTAL HEALTH PROGRAM IN JAPAN}

${ }^{1} \mathrm{~N}$ Kawakami ${ }^{*},{ }^{1} \mathrm{~K}$ Imamura, ${ }^{1} \mathrm{Y}$ Asai, ${ }^{1} \mathrm{~K}$ Watanabe, ${ }^{2} \mathrm{~A}$ Tsutsumi, ${ }^{2} \mathrm{~A}$ Shimazu, ${ }^{2} \mathrm{~A}$ Inoue, ${ }^{3} \mathrm{H}$ Hiro, ${ }^{4} \mathrm{Y}$ Odagiri, ${ }^{5} \mathrm{~T}$ Yoshikawa, ${ }^{6} \mathrm{E}$ Yoshikawa. ${ }^{1}$ Graduate School of Medicine, The University of Tokyo, Tokyo, Japan; ${ }^{2}$ Kitasato University, Sagamihara, Japan; ${ }^{3}$ University of Occupational and Environmental Health, Kitakyushu, Japan; ${ }^{4}$ Tokyo Medical University, Tokyo, Japan; ${ }^{5}$ National Institute of Occupational Safety and Health, Kawasaki, Japan; ${ }^{6}$ Japanese Red Cross College of Nursing, Tokyo, Japan

\subsection{6/oemed-2018-ICOHabstracts.444}

Introduction The Stress Check Program mandates workplaces with 50 or more employees in Japan to provide their employees with an opportunity for a stress survey (the stress check), followed by a doctor interview for employees with high stress. Improvement of psychosocial work environment based on analysis of the stress check data is also recommended. The program went into its first year round between December 2015 and November 2016. The current paper overviews the implementation and effectiveness of the program in the first year.

Methods We reviewed reports from prefectural (local) labour bureaus wherever available. A prospective study of workplaces $(n=217)$ randomly selected was conducted to know the implementation and related costs. A prospective study of an internet sample of full-time workers $(n=2500)$ was also conducted to know the effects of the program for improving psychological distress. A workshop was held to listen to occupational health professionals and human resource personnel who engaged in running the program at their workplaces.

Result Prefectural labour bureaus reported that about $80 \%$ of workplaces implemented the program; the participation rate to the stress check was high (74\% to 94\%); only a small proportion of employees with high stress took the doctor interview. A similar pattern was found in the workplace cohort. In the cohort of workers, psychological distress was improved in a group that participated in the stress check and experienced work environment improvement significantly better than in a control group who did neither. Occupational health professionals had some difficulties in implementing the new program in the first year, while they planned to improve their practice in the second year.

Discussion The Stress Check Program was well implemented in the first year, while the beneficial effect of the program may be limited to those who experienced work environment improvement following the stress check.

\section{AN ERGONOMIST IN A CONTINUOUS IMPROVEMENT TEAM. LESSONS LEARNED FROM THE AVIATION MAINTENANCE INDUSTRY}

J Carmo*, M Lima. ,2UCS- Integrated Healthcare SA, TAP Portugal Group, Lisbon, Portugal

10.1136/oemed-2018-ICOHabstracts.445 